\title{
Agrochemical control of gene expression using evolved split RNA polymerase
}

\author{
Yuan Yuan ${ }^{1}$, Jin Miao ${ }^{2 *}$
}

1, Department of Neurophysiology and Neuropharmacology, Institute of Special Environmental Medicine and Co-innovation Center of Neuroregeneration, Nantong University, Nantong, China.

\section{2, School of Life Sciences, Nantong University, Nantong, China.}

*miaojin@ntu.edu.cn

\begin{abstract}
Chemical induced gene expression is a valuable tool for gene function study. However, most chemical inducers are confined to certain groups of organisms. We engineered a mandipropamid induced gene expression system (Mandi-T7) based on evolved split T7 RNAP system. We showed Mandi-T7 could modulate bacterial gene expression in planta.
\end{abstract}




\section{Introduction}

Chemical-induced gene expression is a powerful tool that allows conditional control over gene expression and facilitates study of toxic and essential genes. However, most chemical inducible systems are often designed to control gene expression in a single group of organisms in the laboratory condition. Working in complex context, like symbiosis between plant and bacteria, requires new chemical inducers that are neutral to different groups of organisms. Agrochemicals are attractive candidates because of their specific mode of action, low toxicity, and drug-like physical properties. Mandipropamid is the active gradient of oomyceticide $\operatorname{REVUS}^{\circledR}$ and has been repurposed to control drought tolerance of plants through orthogonal control strategy (Park et al., 2015). Mandipropamid binds a hextuple mutant of Abscisic acid (ABA) receptor PYR1 (PYR1 ${ }^{\text {MANDI}}$ ) and induces dimerization of PYR1 ${ }^{\text {MANDI }}$ with protein phosphatase HAB1 or ABI1 (Park et al., 2015). RNA polymerases which are modulated by proteinprotein interaction would be desirable for coupling with Mandipropamid-sensing module to activate gene transcription. Split T7 RNA Polymerase (RNAP) has been evolved to be a proximity-dependent biosensor platform, which could transduce protein-protein interaction of light or small molecule sensing modules into activation of gene expression under the control of T7 promoter (Pu et al., 2017). ABA inducible CRISPR/Cas9 gene editing in mammalian cells has been demonstrated using this evolved split T7 RNAP system (Pu et al., 2018). Engineering Mandipropamid induced gene expression is feasible by modifying abscisic acid sensing module. Here, we report the repurposing of Mandipropamid to activate gene expression using the evolved split T7 RNA polymerase (Mandi-T7) and demonstrate the ability to regulate bacteria gene expression in planta.

\section{Results and Discussion}

To simplify circuit design and troubleshooting, we deployed the Mandi-T7 driver module and reporter module on two compatible plasmids. For the reporter module, expression of superfolder Green Fluorescent Protein (sfGFP) was driven by the T7 promoter. For the driver module, we followed the reported architecture of split T7 RNAP (Pu et al., 2018). Briefly, we fused PYR1 ${ }^{\text {MANDI }}$ to the RNAP Cterminal half (T7 RNAPC) and the evolved RNAP N-terminal half (eRNAPn) to the N-terminal truncated $A B I 1$ (Figure 1A). We used relatively long flexible linker (12 aa) to fuse PYR1 ${ }^{\text {MANDI }}$ and T7 RNAPc for achieving high-level expression upon induction (Pu et al., 2017). We used the catalytic inactive mutant (D143A) of $A B I 1$ protein (ABI) to minimize unintended effects. To avoid using additional inducer molecules, we used constitutive promoters to drive the expression of Mandi-T7. We chose standard

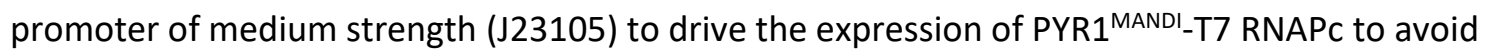
overwhelming the metabolism (Tan et al., 2020). To evaluate the performance of Mandi-T7 system, we measured the response of the Mandi-T7 to different concentration of Mandipropamid. The result showed a dose-dependent response 6 hours post-induction, saturating at $100 \mu \mathrm{M}$ Mandipropamid (Figure 1B and Figure S1). A fold-induction of $44 \mathrm{X}$ was achieved, comparable to previous report (Pu et al., 2018). We failed to detect toxic effect of Mandipropamid on E.coli growth (Figure S2).

In a separate attempt, we tried a circular permutated version of $A B I$ protein, which provides alternative topology for complementation of the split T7 RNAP. We noticed that Ser 234 at the end of helix 2 is closer to the $\mathrm{C}$ terminus of PYR1 ${ }^{\text {MANDI }}$ than the original $\mathrm{N}$-terminus (Figure $\mathrm{S} 3$ ). We joined the original $\mathrm{N}$ and $C$ termini of $A B I$ by a flexible linker and generated the circular permutant CP234, for which Ser234 of $A B I$ serves as the new $\mathrm{N}$-terminus (Figure $1 C$ ). To test the retention of the activity to bind PYR1 ${ }^{\text {MANDI }}$, we used the tripartite split-GFP based system because of its low background fluorescence and minimal 
effect on fusion protein (Cabantous et al., 2013). We observed concentration dependent increase in GFP florescence after Mandipropamid induction (Figure S4). This result indicated that ABI-CP234 retained the ability to interact with PYR1 ${ }^{\text {MANDI }}$ in the presence of Mandipropamid. Next, we adapted ABI-CP234 to the evolved split T7 RNAP system (CP234-Mandi-T7), replacing ABI using ABI-CP234. The result also showed strong sfGFP expression upon Mandipropamid induction like the Mandi-T7 system (Figure 1D and Figure S1).

To provide a proof-of-principle that Mandi-T7 is useful in more complex setting, we evaluated the ability of Mandi-T7 to induce bacterial gene expression inside plant tissues. We infiltrated rosette leaves of Arabidopsis with E.coli culture harboring Mandi-T7 and sfGFP reporter and applied Mandipropamid on the abaxial leaf surface. After 3 hours, we assayed GFP florescence under confocal microscopy. The autofluorescence of chloroplast in the plant cells provided a high-contrast background for observing GFP fluorescence. The result showed that under low excitation intensity, more GFP-positive E.coil cells could be observed inside the induced leaves than inside the control leaves (Figure 1E and Figure S5). The intensity of GFP fluorescence was also higher after induction (Figure S5). Basal level expression of GFP in the control groups was observable at higher excitation intensity and used here to count the E.coli cell number (Figure S5). This result suggested that Mandi-T7 has the potential to enable manipulation of gene expression of plant-associated bacteria.

In summary, this study provides a new tool for agrochemical control gene expression. We showed that Mandipropamid inducible gene expression can be readily built based on the evolved split T7 RNAP system. T7 RNAP is orthogonal and widely applicable to many prokaryotic and eukaryotic organisms. Mandi-T7 can be further integrated with other tools like CRISPRi technology. Low toxicity, easy absorption, and cost-effectiveness of Mandipropamid will give Mandi-T7 leverage in other complex contexts like vector-borne bacterial plant pathogens. We also tested alternative topology (ABI-CP234) for generating $A B I$ fusion protein and hope this result might help expand Mandipropamid to other proximity-dependent systems. CP234-ABI might also be applicable to sensing phytohormone ABA through binding PYR1 family proteins. The reporter signal in uninduced conditions could be caused by constitutive expression of Mani-T7 module and low level self-assembly of split T7 RNAP. Further engineering efforts like directed evolution are needed to lower the basal expression level and increase the dynamic range. We hope the Mandi-T7 system will expand rational control over gene expression to diverse biological context. 


\section{Methods}

Plasmid construction

All genetic parts were synthesized and cloned into vectors by Genscript Biotechnology Inc. (Nanjing, China). Plasmid pET23a(+) was used to clone the Mandipropamid-T7 RNAP cassettes. And the backbone of compatible plasmid pCDFduet-1 was used to clone the T7pro-sfGFP reporter cassette. Sequence of all genetic parts were described in Table S1 and Table S2.

Mandipropamid responsive assay for evolved split T7 RNA polymerase

Both driver and reporter plasmids were co-transformed into E. coli strain Top10 (TIANGEN biotech., Beijing, China). Single colonies were inoculated 2 XYT medium with antibiotics at $37^{\circ} \mathrm{C}$. Overnight culture was transferred to fresh medium with antibiotics at 1:400 ratio. At the same time, Mandipropamid (sc-235565, Santa Cruz) or DMSO (solvent control) was added. The culture was incubated for 6 hours, and $100 \mu \mathrm{L}$ of each sample was added to a 96 well plate and mixed with $190 \mu \mathrm{L}$ 0.1\% Tween-80. Both GFP florescence (Ex: 488, Em: 510 ) and $\mathrm{OD}_{600}$ was measured by Perkin Elmer Enspire $^{\mathrm{TM}} 2300$ Multilabel Reader. After the values for medium were subtracted, florescence over $\mathrm{OD}_{600}$ was calculated and compared to that of the DMSO control samples.

Mandipropamid responsive assay for split GFP

Plasmids were transformed into E. coli strain BL21(DE3) (TRANSGEN biotech., Beijing, China). Single colonies were inoculated $2 X Y T$ medium with antibiotics at $37{ }^{\circ} \mathrm{C}$. Overnight culture was transferred to fresh medium at 1:100 ratio. When $\mathrm{OD}_{600}$ reached between 0.4 to 0.6 , IPTG ( $1 \mathrm{mM}$ final) was added to induce expression of GFP1-9. Mandipropamid or DMSO (solvent control) was also added. The culture was incubated for 3 hours, and $100 \mu \mathrm{L}$ of each sample was transferred to a 96 well plate. Both GFP florescence (Ex: 488, Em: 510) and $\mathrm{OD}_{600}$ was measured by Perkin Elmer Enspire ${ }^{\mathrm{TM}} 2300$ Multilabel Reader. After the values for medium were subtracted, florescence over $\mathrm{OD}_{600}$ was calculated and compared to that of the DMSO control sample.

Induction of GFP expression in planta

E. coli Top10 strain containing Mandi-T7 and sfGFP reporter was generated as mentioned above. Overnight culture was transferred to fresh medium at 1:100 ration. When $\mathrm{OD}_{600}$ reached between 0.4 to 0.6 , E. coli cell was washed and resuspended with Murashige and Skoog medium (MS). Infiltration of E. coli cells into the abaxial side of Arabidopsis leaves was performed using a needless $1 \mathrm{~mL}$ syringe. Either Mandipropamid (400 $\mu \mathrm{M}$ Mandipropamid and 0.1\% Silwet L-77) or mock (0.2\% DMSO and 0.1\% Silwet L-77) was applied on the abaxial surface of infiltrated leaves. After 3 hours GFP fluorescence was imaged by Confocal microscope (Leica SP8). Representative image from 3 different positions was shown. Z-stack of the same thickness was merged using the 'MAX' method (Leica LAS X). The fluorescence intensity and cell number were analyzed using ImageJ (version 1.53i).

\section{Acknowledgements}

We would like to thank Dr. Jinyue Pu and Professor Bryan Dickinson for sharing plasmids and vector information. We also want to thank Dr. Xin Zhou for technical help with Confocal imaging. This work was partly supported by the National Natural Science Foundation of China (Grant 31500690 to J. M.). 


\section{References}

[1] Park, S. Y., Peterson, F. C., Mosquna, A., Yao, J., Volkman, B. F., and Cutler, S. R. (2015). Agrochemical control of plant water use using engineered abscisic acid receptors. Nature, 520, 545-548.

[2] Pu, J., Zinkus-Boltz, J., and Dickinson, B.C. (2017). Evolution of a split RNA polymerase as a versatile biosensor platform. Nat Chem Biol, 13, 432-438.

[3] Pu, J., Kentala, K., and Dickinson, B. C. (2018). Multidimensional control of cas9 by evolved RNA polymerase-based biosensors. ACS Chem Biol, 13, 431-437.

[4] Tan, S. I., and Ng, I. S. (2020). New insight into plasmid-driven T7 RNA polymerase in Escherichia coli and use as a genetic amplifier for a biosensor. ACS Synth Biol, 9, 613-622.

[5] Cabantous, S., Nguyen, H. B., Pedelacq, J. D., Koraïchi, F., Chaudhary, A., Ganguly, K., Lockard, M.A., Favre, G., Terwilliger, T.C., and Waldo, G.S. (2013). A new protein-protein interaction sensor based on tripartite split-GFP association. Sci Rep, 3, 2854.

\section{Figure legend}

Figure 1, Engineering Mandi-T7 and its application. A, schematic of Mandi-T7 system and GFP reporter under control of T7 promoter. Bent arrow: promoter; Box arrow: CDS; Large T-shape: terminator. B, dose-response curve of Mandi-T7 in E. coli Top10. C, schematic of CP234-Mandi-T7. The original termini of $A B I$ were linked by a flexible linker. D, dose-response curve of CP234-Mandi-T7 in E. coli Top10. E, Exogenous control E. coli gene expression in planta. Bar: $50 \mu \mathrm{m}$. 
bioRxiv preprint doi: https://doi.org/10.1101/2021.05.03.442273; this version posted May 3, 2021. The copyright holder for this preprint (which $\longrightarrow$ was not certified by peer review) is the author/funder.
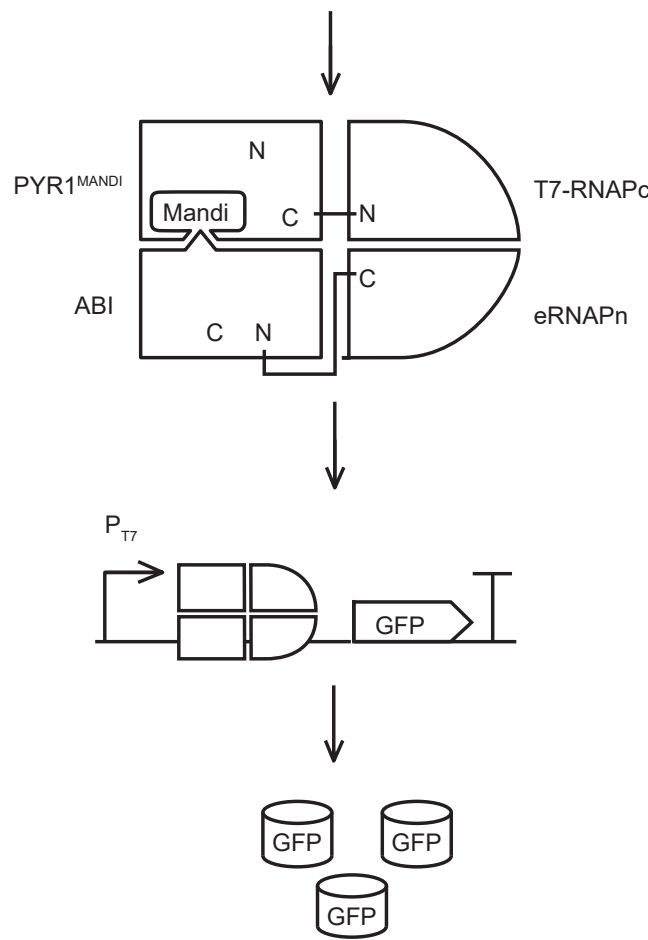

B

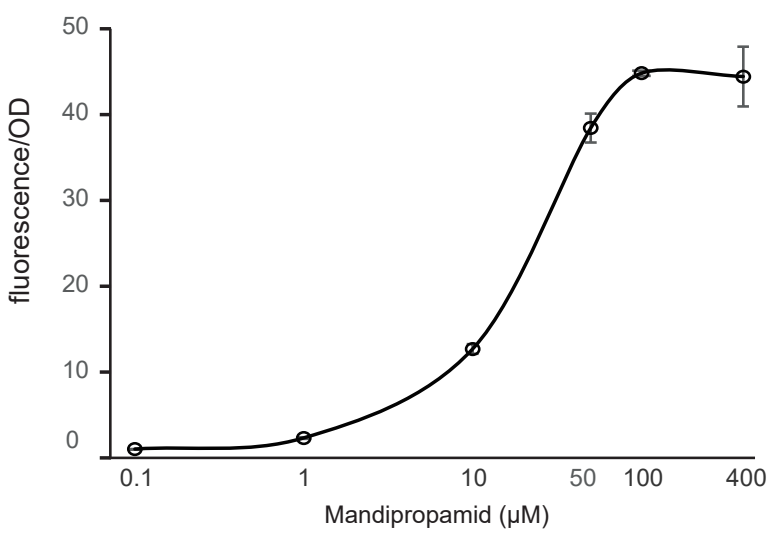

D
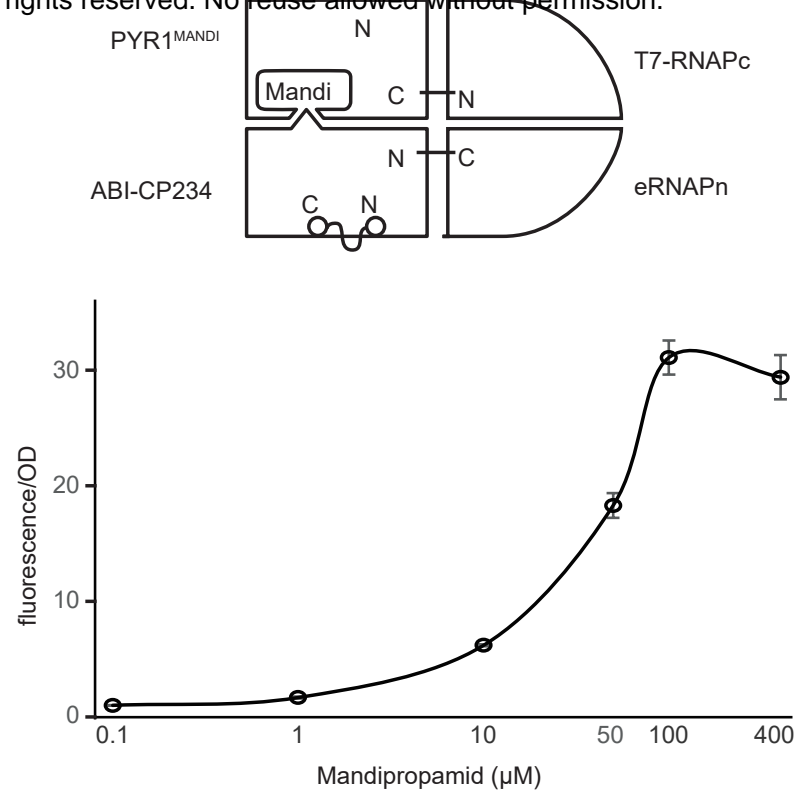

E
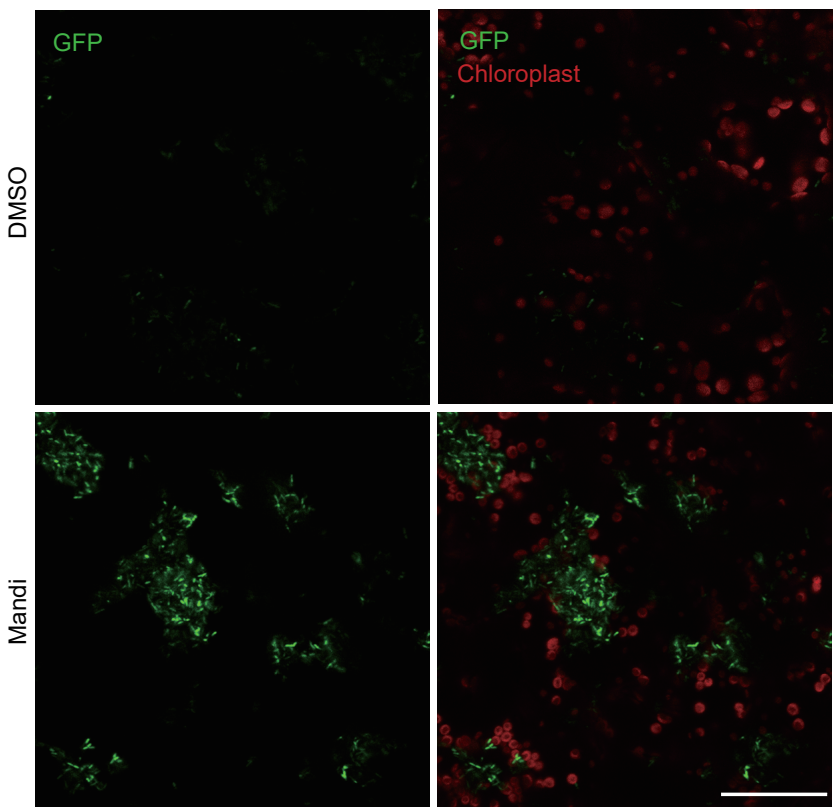